\title{
Some heterocyclic thione derivatives exhibit anticoccidial activity by inhibiting glycosidases
}

\author{
Mahmoud Balbaa ${ }^{1, \#}$, Neama Abd El-Hady', Nabil Taha² and El Sayed H. El Ashry ${ }^{3}$ \\ ${ }^{1}$ Biochemistry Department, Faculty of Science, Alexandria University, Alexandria, Egypt; ${ }^{2 B i o c h e m i s t r y ~ D e p a r t m e n t, ~ E d f i n a ~ F a c u l t y ~ o f ~ V e t e r i n a r y ~}$ \\ Medicine, Alexandria University, Alexandria, Egypt; ${ }^{3}$ Chemistry Department, Faculty of Science, Alexandria University, Alexandria, Egypt
}

\begin{abstract}
Coccidiosis is one of the most common parasitic diseases affecting many species of domestic animals. This disease has a major economic significance and the search for new compounds having anticoccidial activity is of great importance. In this article, different levels of protection from coccidian infection by Eimeria stiedae were developed in rabbits by treatment with compounds incorporating the skeleton of thiourea. These compounds include 4,5-diphenylimidazole-2-thione (1), 4,5-Diphenyl1,2,4-triazole-3-thiol (2) and 5-(2-Hydroxyphenyl)-4-phenyl-1,2,4-triazole-3-thiol (3) compared to the anticoccidial drug toltrazuril as a reference compound. Compounds 1-3 inhibit coccidiosis-induced activity of a-glucosidase. The protection from coccidial infection by compound 1 was higher than that shown for compounds 2 and 3. These data suggest that diazole and triazole thione derivatives have a mimetic effect for anticoccidial drugs through their inhibition of glycosidases.
\end{abstract}

Key words: Coccocidiosis, anticoccidial compounds, imidazolethione, triazolethiol, toltrazuril, inhibitor of glycosidase

Received: 12 February, 2012; revised: 10 June, 2012; accepted: 22 August, 2012; available on-line: 16 October, 2012

\section{INTRODUCTION}

Coccidiosis is one of the most common and problematic parasitic diseases in all classes of domestic animals caused by several species of coccidia (Tolebi and Mulcahy, 1995). It is a ubiquitous protozoan infection of animals seriously impairing their growth and food utilization (Abdel-Megeed et al., 2005) and causes significant mortality in domestic rabbits (Hauptman et al., 2001). Hepatic coccidiosis (Eimeria stiedae) is one of the most pathogenic coccidian protozoans in domestic rabbits causing severe coccidiosis and increased mortality (Hauptman et al., 2001). Consequently the search for new compounds having anticoccidial activity is of prime significance for scientific and economic values. There are many well-known anticoccidial agents such as toltrazuril which is a triazinetrione derivative. It acts on all intracellular development stages of the infection (Mathis et al., 2004) and is used for the treatment of Eimeria stiedae infection (Cam et al., 2008). Since coccidiosis occurs in the liver of the host, it is interesting to study the effect of drugs used for treating the illness on some hepatic enzymes. Glycosidases are important enzymes in processing cellular as well as extracellular carbohydrates (Zhao et al., 2010) and the activity is affected by coccidiosis (Major and Ruff, 1978; Kudweis et al., 1991; Adams et al., 1996).
Glycosidases (EC 3.2.1.-) are enzymes hydrolyzing $O$ - and $S$-glycosyl residues involved in the biosynthesis of oligosaccharide chains and N-linked glycoproteins in the endoplasmic reticulum (Helenius and Aebi, 2001; Long et al., 2006; Yusa et al., 2006). In addition, inhibition of these glycosidases has various effects (Nadanaka et al., 2004; Goffard et al., 2005; Torrelles et al., 2006). Recently, we have reported the glycosidase inhibition activity of 4,5-diphenylimidazole-2-thione (compound 1), 4,5-diphenyl-1,2,4-triazole-3-thiol (compound 2), and 5-(o-hydroxyphenyl)-4-phenyl-1,2,4-triazole-3-thiol (compound 3) (Balba et al., 2011). The objective of the present study is to evaluate the anticoccidial activity of these compounds compared to toltrazuril through the inhibition of coccidiosis-induced elevation of $\alpha$-glucosidase and $\alpha$-amylase, taking into consideration the presence of thiourea moiety in their cyclic structure (Fig. 1). The ultimate goal is to look for some new effective anticoccidial compounds.

\section{MATERIALS AND METHODS}

Materials. The enzymatic colorimetric assay kit for glucose (phenol, 4-amino-antipyrine, glucose oxidase and peroxidase) was purchased from Boehringer (Mannheim, Germany). Bovine serum albumin (BSA), soluble starch and Foline-Ciocalteau reagent were purchased from Sigma (St. Louis, Mo., USA). Toltrazuril was a kind gift from the Department of Poultry and Fish Diseases, Edfina Faculty of Veterinary Medicine, Alexandria University. Other reagents were of analytical grade. Compounds 1, 2 and 3 were prepared according to the methods described by El Ashry et al. (2008 \& 2010).

Animals. Male Spanish V. line rabbits were obtained from the animal house of the Faculty of Agriculture, Alexandria University. The animals were one month old with an approximate body weight of $1000 \mathrm{~g}$. They were housed individually in metal cages and kept healthy under conventional conditions of temperature, humidity and $12 \mathrm{~h}$ photoperiod. Animal work was conducted in

e-mail: m_balbaa@hotmail.com; m.balbaa@bau.edu.lb

\#Present Address: Faculty of Science, Beirut Arab University, Beirut, Lebanon

Abbreviations: Compound 1, 4,5-diphenylimidazole-2-thione; compound 2, 4,5-Diphenyl-1,2,4-triazole-3-thiol, compound; 3, 5-(2-Hydroxyphenyl)-4-phenyl-1,2,4-triazole-3-thiol; PI, post infection; NINM, non-infected non-medicated; INM, infected non-medicated; NIM1, non-infected medicated with compound 1; NIM2, non-infected medicated with compound 2; NIM3, non-infected medicated with compound 3; IM1, infected medicated with compound 1; IM2, infected medicated with compound 2; IM3, infected medicated with compound 3; NIMR, non-infected medicated with toltrazuril; IMR, infected medicated with toltrazuril. 
<smiles>Cc1cc(-n2c(=O)[nH]c(=O)n(C)c2=O)ccc1Oc1ccc(SC(F)(F)F)cc1</smiles>

Toltrazuril<smiles>NC(=S)S</smiles>

Thiourea<smiles>S=c1[nH]c(-c2ccccc2)c(-c2ccccc2)[nH]1</smiles>

(1)

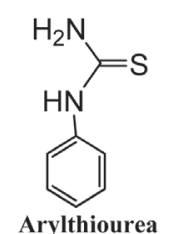<smiles>[R]c1ccccc1-c1nnc(S)n1-c1ccccc1</smiles>

(2) $\mathrm{R}=\mathrm{H}$

(3) $\mathrm{R}=\mathrm{OH}$

Figure 1. Structures of toltrazuril and the investigated thiourea analogues.

accordance with the institution protocol and the national legal requirements.

Infection and medication of animals. Isolation and sporulation of E. stiedae oocysts: E. stiedae was isolated from infective field cases. The isolated oocysts of E. stiedae strain were developed to sporulated oocysts (infective stage), where the optimal conditions for sporulation are $38^{\circ} \mathrm{C}$ and a relative humidity of $76-80 \%$. Complete sporulation was taking place after 72 hours.

Propagation of pure $\boldsymbol{E}$. stiedae strain. Baby rabbits infected with 50000 sporulated oocysts showed symptoms of liver coccidiosis after 15 days post infection (PI). The symptoms were observed as loss of appetite, emaciation, diarrhea and distended abdomen. An enlarged greenish pale liver with whitish yellow necrotic nodules of various sizes on the surface was noticed (data not shown) and ascites also occurred. Fresh and pure oocysts of E. stiedae strain were reisolated from the gall bladder 30 days PI and then were sporulated. The

obtained fresh and sporulated oocysts were used for experimental infection of rabbits.

Experimental observation. The rabbits were divided into ten groups (five for each) as non-infected nonmedicated (NINM, group 1), infected non-medicated (INM, group 2), non-infected medicated with compound 1 (NIM1, group 3), non-infected medicated with compound 2 (NIM2, group 4), non-infected medicated with compound 3 (NIM3, group 5), infected medicated with compound 1 (IM1, group 6), infected medicated with compound 2 (IM2, group 7), infected medicated with compound 3 (IM3, group 8), non-infected medicated with toltrazuril (NIMR, group 9) and infected medicated with toltrazuril (IMR, group 10). The infected groups 2, 6, 7, 8 and 10 were infected by 50000 fresh, sporulated E. stiedae oocysts. The inoculation of the oocysts was carried out orally as a single dose using a wide-mouthed $1.0 \mathrm{ml}$ plastic pipette. At the 5 th day PI, the animals were treated with a specific amount of each compound $\left(10 \%\right.$ of $\left.\mathrm{LD}_{50}\right)$ divided in three doses given once daily. Groups 3 and 6 were treated with $20.4 \mathrm{mg}$ of compound 1 per rabbit (three doses of $6.8 \mathrm{mg}$ ). Groups 4 and 7 were treated with $10.7 \mathrm{mg}$ of compound 2 (3.6 mg per dose). Groups 5 and 8 were treated with $15.5 \mathrm{mg}$ of compound 3 (5.16 $\mathrm{mg}$ per dose). Groups 9 and 10 were treated with $2.5 \%$ toltrazuril by adding the drug solution to the drinking water at the rate of $3 \mathrm{ml} / \mathrm{L}$ for treatment period of $8 \mathrm{~h}$ per day during two consecutive days as reported previously (Mathis et al., 2004).

After different periods PI, up to 30 days, (starting 24 $h$ post treatment with the third dose of the compounds 1, 2 or 3), three rabbits from each group were sacrificed and their livers were collected, excised and subjected to assays. In the positive control group (group 2), signs of disease were observed on the 15th day PI. These were loss of appetite, emaciation, diarrhea and distended abdomen. The signs of disease were observed later (20th day PI) in the IM1, IM2 and IM3 groups. They were of considerably variable intensity, from light in IM1 group to moderate in the IM2 and IM3 groups. In the IMR group and in the non-infected groups, neither clinical symptoms nor side effects were observed throughout the observation period (30th day PI).

Enzymes assay. The assay of $\alpha$-glucosidase activity in the serum and liver homogenate is based on its effect towards maltose as a substrate (Balbaa et al., 2002, Dahlquist, 1970) and the determination of the liberated glucose with the glucose oxidase method as described previously (Tinder, 1969). Briefly, the assay mixture contained $28 \mathrm{mM}$ maltose and $50 \mathrm{mM}$ maleate at $\mathrm{pH} 4.5$. The reaction was run for $60 \mathrm{~min}$ at $37^{\circ} \mathrm{C}$ in a final volume of $1.1 \mathrm{ml}$ with an appropriate amount of the en-

Table 1. Oocysts output by infected rabbits.

\begin{tabular}{|c|c|c|c|c|c|c|c|c|}
\hline \multirow{2}{*}{$\begin{array}{l}\text { Groups/ } \\
\text { days PI }\end{array}$} & \multicolumn{8}{|c|}{ Mean oocyst output $\times 10^{3} / \mathrm{g}$ feces \pm S.E.* } \\
\hline & 16 & 18 & 20 & 22 & 24 & 26 & 28 & 30 \\
\hline 2: INM & $28.4 \pm 0.406$ & $92.0 \pm 0.108$ & $156.0 \pm 0.807$ & $238.1 \pm 0.377$ & $318.5 \pm 0.513$ & $\begin{array}{c}398.6 \pm 0.664 \\
0.0721\end{array}$ & $364.5 \pm 0.377$ & $375.0 \pm 0.513$ \\
\hline 6: IM 1 & $18.2 \pm 0.409$ & $43.4 \pm 0.669$ & $88.1 \pm 0.378$ & $142.5 \pm 0.806$ & $205.1 \pm 0.604$ & $192.3 \pm 0.116$ & $156.0 \pm 0.886$ & $163.1 \pm 0.166$ \\
\hline 7: IM 2 & $20.7 \pm 0.203$ & $56.0 \pm 0.403$ & $102.0 \pm 0.813$ & $164.3 \pm 0.197$ & $222.3 \pm 0.392$ & $258.1 \pm 0.803$ & $218.4 \pm 0.15$ & $238.0 \pm 0.206$ \\
\hline 8: IM 3 & $22.5 \pm 0.204$ & $74.0 \pm 0.102$ & $128.0 \pm 0.148$ & $180.1 \pm 0.132$ & $238.0 \pm 0.146$ & $266.0 \pm 0.102$ & $296.0 \pm 0.176$ & $250.4 \pm 0.148$ \\
\hline 10: IMR & Non & Non & Non & Non & Non & Non & Non & Non \\
\hline
\end{tabular}

*The values are the means of five rabbits \pm S.E. 
Table 2. Serum a-glucosidase in all experimental groups of rabbits.

\begin{tabular}{|c|c|c|c|c|c|}
\hline \multirow{2}{*}{ Groups/days PI } & \multicolumn{5}{|c|}{ Specific activity of serum a-glucosidase ( $\mu \mathrm{M} / \mathrm{min} / \mathrm{mg}$ protein $) \pm$ S.E. ${ }^{*}$} \\
\hline & 1 & 8 & 15 & 22 & 30 \\
\hline 1: NINM & $21.19 \pm 0.19$ & $21.99 \pm 0.14$ & $22.19 \pm 0.04$ & $21.8 \pm 0.16$ & $22.14 \pm 0.07$ \\
\hline 2: INM & $20.38 \pm 0.10$ & $29.30 \pm 0.11^{\mathrm{a}}$ & $36.48 \pm 0.11^{\mathrm{a}}$ & $43.55 \pm 0.07^{a}$ & $38.48 \pm 0.01^{\mathrm{a}}$ \\
\hline 3: NIM 1 & $19.8 \pm 0.20$ & $15.67 \pm 0.34^{b}$ & $19.62 \pm 0.08^{b}$ & $20.65 \pm 0.04^{b}$ & $21.30 \pm 0.11^{\mathrm{b}}$ \\
\hline 4: NIM2 & $20.94 \pm 0.15$ & $17.03 \pm 0.06^{\mathrm{b}}$ & $19.88 \pm 0.08^{b}$ & $20.46 \pm 0.04^{b}$ & $21.76 \pm 0.01^{b}$ \\
\hline 5: NIM 3 & $20.63 \pm 0.16$ & $16.25 \pm 0.07^{b}$ & $18.70 \pm 0.10^{b}$ & $19.45 \pm 0.06^{b}$ & $21.12 \pm 0.02^{\mathrm{b}}$ \\
\hline 6: IM 1 & $20.78 \pm 0.16$ & $23.92 \pm 0.14 c$ & $25.28 \pm 0.03^{c}$ & $28.17 \pm 0.07 c$ & $26.14 \pm 0.03 c$ \\
\hline 7: IM 2 & $20.98 \pm 0.17$ & $24.53 \pm 0.13 c$ & $27.57 \pm 0.08 c$ & $30.25 \pm 0.03 c$ & $27.69 \pm 0.01^{c}$ \\
\hline $8: \operatorname{IM~} 3$ & $20.50 \pm 0.13$ & $26.54 \pm 0.13^{c}$ & $30.56 \pm 0.04^{b}$ & $32.27 \pm 0.05^{c}$ & $29.49 \pm 0.02^{c}$ \\
\hline 9: NIMR & $20.45 \pm 0.15$ & $20.92 \pm 0.06$ & $21.43 \pm 0.13$ & $20.75 \pm 0.06$ & $21.01 \pm 0.03$ \\
\hline 10: IMR & $20.68 \pm 0.22$ & $21.63 \pm 0.13$ & $23.16 \pm 0.03$ & $22.70 \pm 0.04$ & $21.57 \pm 0.07$ \\
\hline
\end{tabular}

*The values are the means of five rabbits \pm S.E. Means in the same column with different superscripts are significantly different $(P<0.05)$.

zyme source and the produced red color was measured at $500 \mathrm{~nm}$. The assay of $\alpha$-amylase in serum as well as in liver homogenate of rabbit was determined according to the method described previously (Bernfeld, 1995; Fischer and Stein, 1961). The reaction was carried out by incubating $5.0 \mathrm{ml}$ of $0.02 \mathrm{M}$ sodium phosphate buffer, $\mathrm{pH} 6.9,2.0 \mathrm{ml}$ of buffered soluble starch and $1.0 \mathrm{ml}$ of sodium chloride in a water bath at $37^{\circ} \mathrm{C}$ for $5 \mathrm{~min}$. A volume of $0.5 \mathrm{ml}$ of diluted enzyme source was then added to the sample tube while $0.5 \mathrm{ml}$ of phosphate buffer was added to the blank one. The assay mixture was incubated for $30 \mathrm{~min}$ at $37^{\circ} \mathrm{C}$ followed by the addition of $0.5 \mathrm{ml}$ of dinitrosalicylic acid reagent to stop the reaction. After heating in a boiling water bath for 5 min, $0.5 \mathrm{ml}$ of sodium hydroxide was added, heated for further $5 \mathrm{~min}$ and cooled under tap water. Finally, the amount of maltose liberated was measured at $540 \mathrm{~nm}$ against blank. Maltose concentration was calculated from a standard curve. All assays were run in triplicate and the average was calculated.

Protein determination. The protein content of serum and tissue samples was determined as reported previously (Tsuyosh \& James, 1978) for calculating the values of the specific activity of the studied enzymes.

\section{RESULTS}

\section{Mortality of rabbits}

Throughout the experimental observation period, no death occurred in the non-infected groups (NINM, NIM1, NIM2, NIM3 and NIMR) or in the IMR group (infected reference group). This result agrees with that reported previously (Pommier et al., 2003). On the other hand, in the INM group (positive control group), four rabbits died, one each on the 20th, 23rd, 25th and 28th day of PI. Moreover, in the IM1 group one rabbit died on the 26th day PI. In IM2 group one rabbit died on the 24th and a second one on the 29th day PI. In group 8 (IM3), one rabbit died on day 23rd day of PI and second rabbit on the 28th day. Thus, the mortality was
80, 20, 40, 40 and 0 percentage in the INM, IM1, IM2, IM3 and IMR groups, respectively. These data show that compound 1 significantly reduced the mortality caused by E. stiedae as compared with the positive control group.

\section{Parasitological observation}

We noted a nearly complete absence of oocysts in the non-infected groups (NINM, NIM1, NIM2, NIM3 and NIMR). In the positive control (INM), the peak production of was at the 26th day PI, and then decreased (Table 1). The mean of oocysts abundance per gram feces was $28.4 \pm 0.406$ on the 16th day PI increased to $398.6 \pm 0.664$ at the 26th day PI and then decreased to $364.5 \pm 0.377$ on the 28th day PI in agreement with previous studies by others (Jenkins et al., 1993). In the IM1 group, the peak period of oocyst output reached maximum on the 24th day PI and then decreased. The peak periods of oocysts output of the IM2 and IM3 groups reached to maximum in the 26th and 28th days of PI, respectively, then decreased (Table 1). Thus, compounds 1,2 and 3 caused a significant decrease $(P=0.001)$ of the oocyst output as compared to positive control but did not prevent it. No oocysts were found in the fecal samples from the IMR group throughout the experiment.

\section{Serum and hepatic a-glucosidase and a-amylase}

Serum level of a-glucosidase

As shown in Table 2, at the first day PI the specific activity of serum $\alpha$-glucosidase was nearly similar in all experimental groups with non-significant change $(\mathrm{P}=0.1676)$. At the 8th day PI, the positive control group displayed a significant elevation of the specific activity of serum $\alpha$-glucosidase, from $20.38 \pm 0.10$ to $29.30 \pm 0.11(\mathrm{P}=0.0019)$. The specific activity of serum $\alpha$-glucosidase of the INM group was elevated by $33 \%$ compared to the NINM group (negative control group). In addition, the protein content was significantly reduced $(\mathrm{P}=0.0042)$. The specific activity of serum $\alpha$-glucosidase in the NIM1, NIM2, and NIM3 groups was significantly reduced compared to the NINM group $(\mathrm{P}=0.0001)$ by 
Table 3. Serum a-amylase in all experimental groups of rabbits.

\begin{tabular}{|c|c|c|c|c|c|}
\hline \multirow{2}{*}{ Groups/days PI } & \multicolumn{5}{|c|}{ Specific activity of serum a-glucosidase $(\mu \mathrm{M} / \mathrm{min} / \mathrm{mg}$ protein $) \pm$ S.E.* } \\
\hline & 1 & 8 & 15 & 22 & 30 \\
\hline 1: NINM & $11.16 \pm 0.03$ & $11.14 \pm 0.28$ & $10.96 \pm 0.03$ a & $11.17 \pm 0.05^{a}$ & $11.24 \pm 03^{a}$ \\
\hline 2: INM & $10.92 \pm 0.03$ & $12.07 \pm 0.36$ & $12.65 \pm 0.04^{a}$ & $13.48 \pm 0.15^{a}$ & $13.79 \pm 0.05^{\mathrm{a}}$ \\
\hline 3: NIM 1 & $10.68 \pm 0.02$ & $7.64 \pm 0.02 b$ & $9.51 \pm 0.07$ & $10.19 \pm 0.322$ & $10.85 \pm 0.07$ \\
\hline 4: NIM2 & $10.47 \pm 0.11$ & $8.14 \pm 0.04^{b}$ & $9.80 \pm 0.10$ & $10.61 \pm 0.08$ & $10.43 \pm 0.01$ \\
\hline 5: NIM 3 & $10.66 \pm 0.03$ & $8.96 \pm 0.07^{b}$ & $9.60 \pm 0.03$ & $10.11 \pm 0.01$ & $10.23 \pm 0.08$ \\
\hline 6: IM 1 & $11.01 \pm 0.12$ & $10.64 \pm 0.03$ & $10.72 \pm 0.04$ & $11.26 \pm 0.03 a$ & $11.87 \pm 0.03$ \\
\hline 7: IM 2 & $11.20 \pm 0.31$ & $10.72 \pm 0.04$ & $10.88 \pm 0.15^{a}$ & $11.49 \pm 0.09 a$ & $11.86 \pm 0.03$ \\
\hline 8: IM 3 & $11.02 \pm 0.14$ & $11.82 \pm 0.04^{a}$ & $10.85 \pm 0.07 a$ & $11.52 \pm 0.03^{a}$ & $12.16 \pm 0.01$ \\
\hline 9: NIMR & $11.08 \pm 0.02$ & $11.07 \pm 0.03 a$ & $9.99 \pm 0.05^{a}$ & $10.43 \pm 0.07 a$ & $10.66 \pm 0.03$ \\
\hline 10: IMR & $11.03 \pm 0.32$ & $11.94 \pm 0.03 a$ & $10.89 \pm 0.13 a$ & $11.21 \pm 0.04 \mathrm{a}$ & $10.37 \pm 0.02$ \\
\hline
\end{tabular}

*The values are the means of five rabbits \pm S.E. Means in the same column with different superscripts are significantly different $(P<0.05)$.

a value of 30,24 , and $26 \%$, respectively. Groups IM1, IM2 and IM3 showed a slight elevation in the specific activity of serum $\alpha$-glucosidase with a slight reduction of the protein content.

At the 15th day PI, the specific activity of serum $\alpha$-glucosidase in the INM group was continuously elevated by $64 \%$ compared to the negative control group $(\mathrm{P}=0.0001)$. Also, the protein content was significantly reduced. The specific activity of serum $\alpha$-glucosidase in the IM1, IM2 and IM3 groups was elevated $(\mathrm{P}=0.0005)$ by 14,23 and $38 \%$, respectively. On the other hand, the specific activity of serum $\alpha$-glucosidase in the non-infected groups (groups 3, 5, 7 and 9) and the IMR group was not significantly changed $(\mathrm{P}=0.1791)$. At the $22 \mathrm{nd}$ day PI, the specific activity of serum $\alpha$-glucosidase in the INM group was highly elevated by a value of $99 \%$ compared to the negative control group $(\mathrm{P}=0.0001)$. In the IM1, IM2 and IM3 groups, it was elevated by a 29, 38 and $47 \%$, respectively $(\mathrm{P}=0.0001)$. The specific activity of serum $\alpha$-glucosidase in groups $3,5,7,9$ and 10 showed a non-significant difference from the negative control $(\mathrm{P}=0.2729)$.

At the 30th day PI, the elevation of the specific activity of serum $\alpha$-glucosidase in the INM, IM1, IM2 and IM3 groups compared to the negative control group was less than that observed at the 22 nd day PI: 74, 18, 25 and $33 \%$, respectively (Table 2 ). On the other hand, the specific activity of serum $\alpha$-glucosidase in groups $3,5,7,9$ and 10 showed a non-significant change $(\mathrm{P}=0.2002)$. This implies that the specific activity of serum $\alpha$-glucosidase in the non-infected treated groups (NIM1, NIM2 and NIM3) is inhibited by compounds 1, 2 and 3. Also, these compounds lowered the elevation of the specific activity of serum $\alpha$-glucosidase resulting from the hepatic coccidiosis in the infected treated groups (IM1, IM2 and IM3). The inhibition of coccidiosis-induced serum $\alpha$-glucosidase in the IM1, IM2 and IM3 did not bring it to the normal level. The specific activity of the enzyme from the NIMR and IMR groups showed a non-significant change throughout the observation period $(P>0.05)$. The protein content in the serum of these two groups was slightly reduced.
Serum level of a-amylase

The specific activity of serum $\alpha$-amylase from rabbits in all experimental groups was determined weekly throughout the observation period. As shown in table 3 , the specific activity of serum $\alpha$-amylase in the INM group was slightly elevated throughout the observation period by 8,16, 21 and 19\% at 8th, 15th, 22nd and 30th days PI, respectively, comparing to NINM as a negative control. In the IM1, IM2, and IM3 groups it displayed a non-significant change $(P=0.460)$ throughout the observation period, indicating that compounds 1, 2 and 3 prevented effectively the slight increase of the activity induced by the infection. In the NIM1, NIM2 and NIM3 groups, the specific activity of the serum $\alpha$-amylase was reduced at 8 th day PI by 31,27 and $20 \%$, respectively. In groups IMR and NIMR, it was non-significantly changed $(P=0.2002)$ throughout the observation period.

Table 4. Hepatic a-glucosidase and a-amylase in different experimental groups of rabbits at 8 th day PI.

\begin{tabular}{|c|c|c|c|}
\hline \multicolumn{2}{|l|}{ Groups } & \multicolumn{2}{|c|}{ Specific activity $(\mu \mathrm{M} / \mathrm{min} / \mathrm{mg}$ protein $) \pm$ S.E.* } \\
\hline Number & Name & a-Glucosidase & a-Amylase \\
\hline 1 & NINM & $14.53 \pm 0.638$ & $1.113 \pm 0.107$ \\
\hline 2 & INM & $17.41 \pm 0.208^{b}$ & $1.194 \pm 0.227 c$ \\
\hline 3 & NIM1 & $9.27 \pm 0.254^{a}$ & $0.855 \pm 0.226^{a}$ \\
\hline 4 & NIM2 & $10.15 \pm 0.178^{a}$ & $0.808 \pm 0.208^{a}$ \\
\hline 5 & NIM3 & $10.18 \pm 0.146^{a}$ & $0.891 \pm 0.216^{a}$ \\
\hline 6 & IM1 & $13.00 \pm 0.432^{c}$ & $1.061 \pm 0.192^{c}$ \\
\hline 7 & IM2 & $14.19 \pm 0.323 c$ & $1.094 \pm 0.147 c$ \\
\hline 8 & IM3 & $14.08 \pm 0.248^{c}$ & $1.088 \pm 0.266^{c}$ \\
\hline 9 & NIMR & $12.95 \pm 0.178^{c}$ & $1.023 \pm 0.254^{c}$ \\
\hline 10 & IMR & $13.73 \pm 0.216 c$ & $1.114 \pm 0.204 c$ \\
\hline
\end{tabular}

*The values are the means of five rabbits \pm S.E. Means in the same column with different superscripts are significantly different $(P<0.05)$. 
Table 5. Hepatic a-glucosidase and a-amylase in different experimental groups of rabbits at 30th day PI.

\begin{tabular}{llcc}
\hline Groups & & Specific activity $(\mu \mathrm{M} / \mathrm{min} / \mathrm{mg}$ protein $) \pm$ S.E.* \\
\hline Number & Name & a-Glucosidase & a-Amylase \\
\hline 1 & NINM & $15.02 \pm 0.308$ & $1.116 \pm 0.107$ \\
2 & INM & $29.13 \pm 0.392^{\mathrm{a}}$ & $1.294 \pm 0.227^{\mathrm{b}}$ \\
3 & NIM1 & $14.74 \pm 0.334^{\mathrm{b}}$ & $1.025 \pm 0.226$ \\
4 & $\mathrm{NIM2}$ & $13.45 \pm 0.409^{\mathrm{b}}$ & $1.108 \pm 0.108$ \\
5 & $\mathrm{NIM} 3$ & $14.94 \pm 0.324^{\mathrm{b}}$ & $1.021 \pm 0.216$ \\
6 & $\mathrm{IM} 1$ & $19.48 \pm 0.248^{\mathrm{c}}$ & $1.145 \pm 0.192^{\mathrm{b}}$ \\
7 & $\mathrm{IM} 2$ & $21.14 \pm 0.394^{\mathrm{c}}$ & $1.197 \pm 0.141^{\mathrm{b}}$ \\
8 & $\mathrm{IM} 3$ & $22.37 \pm 0.154^{\mathrm{c}}$ & $1.218 \pm 0.266^{\mathrm{b}}$ \\
9 & $\mathrm{NIMR}$ & $13.27 \pm 0.0148^{\mathrm{b}}$ & $1.023 \pm 0.254$ \\
10 & IMR & $14.73 \pm 0.294^{\mathrm{b}}$ & $1.114 \pm 0.204^{\mathrm{b}}$ \\
\hline
\end{tabular}

*The values are the means of five rabbits \pm S.E. Means in the same column with different superscripts are significantly different $(P<0.05)$.

Hepatic a-glucosidase and a-amylase

At the 8 th day PI (24 h post medication) and at 30th day PI (at the end of the observation period), the specific activity of $\alpha$-glucosidase and $\alpha$-amylase was determined in liver homogenateI (Tables 4 and 5). At the 8th day PI, the specific activities of hepatic $\alpha$-glucosidase and $\alpha$-amylase were elevated in the INM group by a value of 20 and $7 \%$, respectively compared to the negative control group. In the IM1, IM2, IM3, IMR and NIMR groups, they showed a non-significant change $(P>0.05)$ compared to the NINM group. The specific activity of hepatic $\alpha$-glucosidase was reduced by 36,30 and $27 \%$, in NIM1, NIM2 and NIM3 groups respectively (significant change compared to INM group, $P<0.05$ ). Also, the specific activity of hepatic $\alpha$-amylase was significantly reduced in the NIM1, NIM2 and NIM3 groups compared to INM group, $P<0.05$ (Table 4).

At the 30th day PI, the specific activity of hepatic $\alpha$-glucosidase in the INM, IM1, IM2 and IM3 groups was significantly elevated compared to the NINM group $(P<0.05)$ while for the hepatic $\alpha$-amylase the elevation was non-significant $(P<0.05)$. The specific activities of hepatic $\alpha$-glucosidase and $\alpha$-amylase in the NIM1, NIM2, NIM3, NIMR and IMR groups displayed a non-significant changes $(P<0.05)$ compared to the NINM group (Table 5). So, both serum and hepatic $\alpha$-amylases were slightly affected by hepatic coccidiosis. The target compounds 1, 2 and 3 reduced the coccidiosis-induced elevation of serum and hepatic $\alpha$-glucosidases and $\alpha$-amylases to a level near that of the non-infected groups.

\section{DISCUSSION}

The ultimate goal of the current study was to establish effective anticoccidial compounds. The efficacy of the tested compounds has been confirmed by many criteria such as weight gain, oocyst counts, parasitological, biochemical, and histopathological findings. The biochemical studies involved serum and hepatic $\alpha$-glucosidase and $\alpha$-amylase. The compounds 1,2 and 3 had structural patterns similar to thioureas and arylthioureas. Similar compounds which have been used as anticoccidial drugs (Sabrina \& Shoaa, 2001).
The toxic effect of the chemical groups or substituents in compounds $\mathbf{1}, 2$ and 3 should be taken into consideration. Recently, we reported that $\mathrm{LD}_{50}$ values for compounds 1, 2 and 3 of $0.204,0.107$ and $0.155 \mathrm{mg} / \mathrm{g}$ body weight, respectively (Balba et al., 2011) and the persistence of those compounds in rabbits was approximately $120 \mathrm{~h}$.

The presented results show that a field strain of Eimeria stiedae was successfully isolated from the gall bladder of infected field cases and sporulated in a similar manner to that described previously (Baghdadi \& AlMathal, 2010). The field strain of E. stiedae was reisolated from experimental animals at 28th day PI. This reisolated strain was confirmed by microscopical examination and its oocysts were formed to be ellipsoidal (data not shown). This is consistent with the results reported by others (Pakes \& Gerrity, 1994). It was reported that stored sporulated oocysts of E. stiedae were viable and infective for up to 18 months at $4^{\circ} \mathrm{C}$ (Drouet-Viard et al., 1997). In the present study, baby rabbits successfully infected by sporulated oocysts were treated with compounds 1,2 or 3 as anticoccidial factors and toltrazuril as a reference. The data for the positive control group, which developed a typical E. stiedae infection, are in agreement with that described previously (Singla et al., 2000).

The infected rabbits treated with the tested compounds were compared with those treated with the reference drug. The mortality decreased from $80 \%$ in the positive control group to 20, 40 and $40 \%$ in the groups treated with compounds 1,2 and 3, respectively, compared to $0 \%$ for toltrazuril (reference drug). In addition, there was a decrease in oocyst output from 100\% in positive control group to $11-54 \%$ in the groups treated by the tested compounds with respect to zero (no oocysts) for toltrazuril. Furthermore, the postmortem examination and histopathological pictures for the groups treated by the tested compounds were clear and the degree of infection was decreased by 36-73\%. Therefore, the prevention of lesion in groups treated by these compounds was significant, especially for compound 1 .

Toltrazuril induced complete protection against $E$. stiedae infection in rabbits (Morton-Smith, 1997; Haberkorn \& Mundt, 1999). The histopathological examination showed all stages of Eimeria protozoan except schizonts in treated animals with compounds $\mathbf{1 ,} 2$ or 3 (not shown). This means these compounds prevent the formation of schizonts, probably through their inhibitory effect on the liver lysosomal $\alpha$-glucosidase, which is involved in wall formation of schizonts or by other mechanisms which may be clarified by further. The results confirmed that toltrazuril induced complete protection against E. stiedae infection as discussed elsewhere (Morton-Smith, 1997; Haberkorn \& Mundt, 1999), while compounds 1, 2 and 3 caused only a partial protection.

In the present study, we report an increase in the activity of hepatic $\alpha$-glucosidase and $\alpha$-amylase in INM as compared to NINM rabbits. Also, we compare the activity of enzymes in IM1, IM2 and IM3 to NINM to detect the reduction of coccidiosis-induced activity. Moreover, the enzyme activities in IM1, IM2 and IM3 are also compared to NIM1, NIN2, NIN3 to confirm the inhibitory effect of the tested compounds. The significant induction of the specific activity of $\alpha$-glucosidase in coccidiosis was significantly reduced in the groups treated with compounds 1, 2 and 3 but not fully to normal values. This reduction indicates that $\alpha$-glucosidase was significantly inhibited by compounds 1, 2 and 3 which lead to decrease the lesion and lowered the side effect of hepat- 
ic coccidiosis. On the other hand, the specific activity of serum $\alpha$-amylase was slightly elevated in the INM group as explained in "Results". That non-significant elevation in hepatic coccidiosis was reduced by compounds 1,2 or 3 nearly to the normal level.

In general, the treatment with compound $\mathbf{1}$ in three successive oral doses on three consecutive days alleviated the clinical symptoms and decreased the mortality from $80 \%$ in the positive control group to $20 \%$. Also, it brought about a significant decrease in oocyst output nine-fold and reduced the elevation of relative specific activity of serum $\alpha$-glucosidase from $99 \%$ in positive control group to $29 \%$. In addition, it decreases the lesion formation by $73 \%$. Taken together, compound 1 offers a protection against hepatic coccidiosis in rabbits, whereas compound 2 and 3 were less effective. However, many synthetic compounds of different structure have been reported to show an anticoccidial activity against different species of Eimeria (Biftu et al., 2005; Yusa et al., 2006; Wang et al., 2009; Zhao et al., 2010).

In conclusion, diaryl derivatives of imidazole-thione and 1,2,4-triazole-thiol which incorporate the thiourea skeleton in their cyclic structure lower the coccidiosis-induced activity of $\alpha$-glucosidase and offer variable degree of protection against that disease Among them, compound 1 seems to be a promising drug for the treatment of coccidiosis by Eimeria stiedae.

\section{Acknowledgements}

The authors thank the technical staff of Departments of Biochemistry at the Faculty of Science and the Edfina Faculty of Veterinary Medicine, Alexandria University for their assistance.

\section{REFERENCES}

Abdel-Megeed KN, Abu El-Ezz NM, Abdel-Rahman EH (2005) Protective effect of Eimeria stiedae coproantigen against hepatic coccidiosis in rabbits. J Egypt Soc Parasitol 35: 581-595.

Adams C, Vahl HA, Veldman A (1996) Interaction between nutrition and Eimeria acervulina infection in broiler chickens: diet compositions that improve fat digestion during Eimeria acervulina infection. $\mathrm{Br} \mathrm{J}$ Nutr 75: 867-873.

Baghdadi HB, Al-Mathal EM (2010) Anti-coccidial effect of Commiphora molmol in the domestic rabbit (Oryctolagus cuniculus domesticus L.). J Egypt Soc Parasitol 40: 653-668.

Balba M, Abdel-Hady N, Taha N, Rezki N, El Ashry ESH (2011) Inhibition of $\alpha$-glucosidase and $\alpha$-amylase by diaryl derivatives of imidazole-thione and 1,2,4-triazole-thiol. Eur J Med Chem 46: 25962601.

Balbaa M, Mansour H, El-Sawy H, El-Ashry ESH (2002) Inhibition of some hepatic glycosidases by the diseco nucleoside, 4-amino3-(D-glucopentitol-1-yl)-5-mercapto-1,2,4-triazole and its 3-methyl analog. Nucleos Nucleot Nucl Acids 21: 695-708.

Bernfeld P (1995) Amylases, alpha and beta. Methods Ensymol 1: 149_ 158.

Biftu T, Feng D, Ponpipom M, Girotra N, Liang GB, Qian X, Bugianesi R, Simeone J, Chang L, Gurnett A, Liberator P, Dulski P, Leavitt PS, Crumley T, Misura A, Murphy T, Rattray S, Samaras S, Tamas T, Mathew J, Brown C, Thompson D, Schmatz D, Fisher M, Wyvratt M (2005) Synthesis and SAR of 2,3-diarylpyrrole inhibitors of parasite cGMP-dependent protein kinase as novel anticoccidial agents. Bioorg Med Chem Lett 15: 3296-3301.

Cam Y, Atasever A, Eraslan G, Kibar M, Atalay O, Beyaz L, Inci A, Liman BC (2008) Eimeria stiedae: experimental infection in rabbits and the effect of treatment with toltrazuril and ivermectin. Exp Parasitol 119: 164-172.

Dahlquist A (1970) Assay of intestinal disaccharidases. Ensymol Biol Clin 11: 52-56.

Drouet-Viard F, Coudert P, Licois D, Boivin M (1997) Vaccination against Eimeria magna coccidiosis using spray dispersion of precocious line oocysts in the nest box. Vet Parasitol 70: 61-66.

El-Ashry ESH, Rashed N, Awad LF, Ramadan E, Abdel-Maggeed SM, Rezki N (2008) Synthesis of 5-aryl-3-glycosylthio-4-phenyl-4h-1,2,4triazoles and their acyclic analogs under conventional and microwave conditions. J Carbohydr Chem 27: 70-85.
El-Ashry ESH, Rashed N, Awad LF, Ramadan E, Abdel-Maggeed SM, Rezki N (2007) MAOS versus conventional synthesis of 4,5-di- and 3,4,5-triphenylimidazole-2-thione and their derivatives. ARKIVOC vii: $30-40$.

Fischer EA, Stein EA (1961) $\alpha$-Amylase from human saliva. Biochem Prep 8: 27-32.

Goffard A, Callens N, Bartosch B, Wychowski C, Cosset FL, Montpellier C, Dubuisson J (2005) Role of N-linked glycans in the functions of hepatitis C virus envelope glycoproteins. J Virol 79: 8400-8409.

Haberkorn A, Mundt HC (1999) Investigation with a broad spectrum anticoccidial agent. Prakt Tierarat 69: 49-51.

Hauptman K, Tichy F, Knotek Z (2001) Clinical diagnostics of hepatopathies in small mammals: evaluation of importance of individual methods. Acta Vet Brno 70: 297-311.

Helenius A, Aebi M (2001) Intracellular functions of N-linked glycans. Science 291: 2364-2369.

Jenkins MC, Seferian PG, Augustine PC, Danforln HO (1993) Protective immunity against coccidiasis elicited by radiation attenuated Eimeria maxima, sporozoites that are incapable a sexual development. Avian Dis 37: 74-82.

Kudweis M, Lojda Z, Julis I (1991) Beta-D-glucosidase in the microvillous zone of small intestine enterocytes in experimental coccidiosis in suckling piglets. Vet Med (Praha) 36: 225-234.

Long G, Westenberg M, Wang H, Vlak JM, Hu Z (2006) Function, oligomerization and N-linked glycosylation of the helicoverpa armigera single nucleopolyhedrovirus envelope fusion protein. J Gen Virol 87: 839-846.

Major JR Jr, Ruff MD (1978) Disaccharidase activity in the intestinal tissue of broilers infected with coccidia. J Parasitol 64: 706-711.

Mathis GF, Froyman R, Kennedy T (2004) Coccidiosis control by administering toltrazuril in the drinking water for 2-day period. Vet Parasitol 121: 1-9.

Morton-Smith C (1997) The treatment of hepatic coccidiosis in rabbits. Vet J 103: 207-213.

Nadanaka S, Yoshida H, Kano F, Murata M, Mori K (2004) Activation of mammalian unfolded protein response is compatible with the quality control system operating in the endoplasmic reticulum. Mol Biol Cell 15: 253-2548.

Pakes SP, Gerrity LW (1994) Protozoal diseases. In The Biology of the Laboratory Rabbit, 2nd edn, pp 205-30, Academic Press, London.

Pommier P, Keita A, Wessel-Robert S, Dellac B, Mundt HC (2003) Efficacy of toltrazuril in the prevention and the treatment of suckling piglets coccidiosis: Results of two field trials. Rev Med Vet 154: 41-46.

Sabrina M, Shoaa Abdul R (2001) Novel compounds, specifically aromatic and heteroaromatic ureas and thioureas, useful against parasites and especially against coccidiosis. PCT Int Appl 12: 72-77.

Scribner A, Meitz S, Fisher M, Wyvratt M, Leavitt P, Liberator P, Gurnett A, Brown C, Mathew J, Thompson D, Schmatz D, Biftu $\mathrm{T}$ (2008) Synthesis and biological activity of anticoccidial agents: 5,6-Diarylimidazo[2,1-b][1,3] thiazoles. Bioorg Med Chem Lett 18: $5263-5267$.

Scribner A, Moore Lii JA, Ouvry G, Fisher M, Wyvratt M, Leavitt P, Liberator P, Gurnett A, Brown C, Mathew J, Thompson D, Schmatz D, Biftu T (2009) Synthesis and biological activity of anticoccidial agents: 2,3-diarylindoles. Bioorg Med Chem Lett 19: 15171521.

Singla LD, Juyal PD, Sandhu BS (2000) Pathology and therapy in naturally Eimeria stiedae — infected rabbits. I Protozoal Res 10: 185191.

Tinder P (1969) Determination of blood glucose using an oxidase-peroxidase system with non carcinogenic chromogen. Ann Clin Biochem 6: $24-29$.

Tolebi A, Mulcahy G (1995) Cross-reactivity among antisera raised against five avian Eimera species in the natural host and in rabbits. Avian Pathol 24: 533-544.

Torrelles JB, Azad AK, Schlesinger LS (2006) Fine discrimination in the recognition of individual species of phosphatidylmyo-inositol mannosides from mycobacterium tuberculosis by $C$-type lectin pattern recognition receptors. J Immunol 177: 1805-1816.

Tsuyosh TO, James TA (1978) Simplified method of aquantitating protein using the biuret and phenol reagent. Ann Clin Biochem 86: 193-205.

Wang YY, Yan CR, Weng YB, Jin H, Chen H (2009) Synthesis and anticoccidial activities of novel ethyl 6-aryloxy-7-bromo-4-hydroxy3-quinolinecarboxylate against Eimeria tenella. Pest Biochem Physiol 93: 85-90.

Yusa A, Kitajima K, Habuchi O (2006) N-Linked oligosaccharides on chondroitin 6-sulfotransferase-1 are required for production of the active anzyme, Golgi localization, and sulfotransferase activity toward keratan sulfate. J Biol Chem 281: 20393-20403.

Zhao W, Li T, Woodward R, Xia C, Wang PG, Guan W (2010) Enzymatic synthesis of complex carbohydrates. In Comprehensive natural products chemistry II: Carbohydrates, nucleosides \& nucleic acids. Mander L, Liu HW eds, pp. 5-54. Elsevier, Oxford. 